\title{
Relationship Between Acrylamide Concentration and Enzymatic Activity in An Improved Single Fibrin Zymogram Gel System
}

\author{
Nack-Shick Choi, Byoung-Young Kim, Jin-Young Lee, Kab-Seog Yoon, \\ Kyoung-Yoen Han and Seung-Ho Kim* \\ Proteome Research Laboratory, Korea Research Institute of Bioscience and Biotechnology, Yusong, Taejon 305-600, Korea
}

Received 13 September 2001, Accepted 17 October 2001

\begin{abstract}
Based on the zymography analysis, Bacillus sp. DJ-4 (screened from Doen-Jang, a Korean traditional fermented food) secretes seven extracellular fibrinolytic enzymes (EFEs; 68, 64, 55, 45, 33, 27, and $13 \mathrm{kDa}$ ) in culture broth. These seven EFEs were analyzed by newly applied SDSfibrin zymography combined with gradient polyacrylamide (SDS-FZGP). This improved gel system was used with a 5-20\% acrylamide gradient in a fibrin zymogram gel for the separation of proteins with molecular masses from below $10 \mathrm{kDa}$ to over $100 \mathrm{kDa}$ on one gel plate. Using this system, high molecular weight bands (HMWBs) were clearly and sharply resolved. We also examined the relationship between an acrylamide concentration and the enzymatic activity of EFE using densitometric analysis.
\end{abstract}

Keywords: Bacillus, Extracellular protease, Fibrin zymography

\section{Introduction}

SDS-polyacrylamide gel is one of the most frequently used and powerful techniques in protein works. Gel electrophoresis of mixed proteins through a linear gradient of polyacrylamide permits an excellent resolution of a broad range $(10-200 \mathrm{kDa})$ of proteins in a single gel (from 15 to $200 \mathrm{kDa}$ on a $5-20 \%$ gel, or 13 to $950 \mathrm{kDa}$ on a 3 to $30 \%$ gel) (Hames, 1981; Walker, 1984).

Bacillus strains are well-known for secreting various extracellular proteases, which contain wide range of proteins with molecular weights that range from $15 \mathrm{kDa}$ to $100 \mathrm{kDa}$ (Burg et al., 1990; Kobayashi et al., 1999; Kim and Choi, 2000; jeong and Han, 2001). In order to detect these Bacillus proteases, zymographic techniques are widely used (Heussen and Dowdle, 1980; Kim et al., 1998; Choi and Kim, 1999;

*To whom correspondence should be addressed.

Tel: 82-42-860-4162; Fax: 82-42-860-4593

E-mail: shkim@kribb4680.kribb.re.kr
Kim and Choi, 1999). These methods are based on a SDSpolyacrylamide gel that is co-polymerized with protein substrates that are degraded by the proteases, which are restored during the incubation period after an electrophoretic separation. Enzymatic activities in the zymogram gel are visualized as clear bands of fibrinolysis against a dark-blue background of undigested fibrin substrate (Kim et al., 1998).

In this report, we introduced an improved technique, SDSFZGP, which combined an acrylamide gradient system with the zymogram gel for an analysis of the total extracellular fibrinolytic enzymes from Bacillus sp. DJ-4 was isolated from Doen-Jang, a Korean traditional fermented food. We also recommend this method as an alternative to the current technique and a routine gel electrophoretic method.

\section{Materials and Methods}

Materials Fibrinogen and thrombin from bovine for fibrin zymography were purchased from Sigma (St. Louis, USA). A gradient system (gradient mixer GM-1 and peristaltic pump P-1) was obtained from Pharmacia (USF). Other chemicals were of analytical grade.

Bacillus sp. DJ-4 and culture Bacillus sp. DJ-4 that was isolated from Doen-Jang, a Korean traditional fermented food (Kim et al., 1998), was grown at $37^{\circ} \mathrm{C}$ in a tryptic soy broth (TSB, Difco) and transferred to $100 \mathrm{ml}$ of fresh media. After a 2-day incubation, the cells were removed from the culture broth by centrifugation at $10,000 \mathrm{~g}$ for $10 \mathrm{~min}$, and the supernatant was used for a fibrin zymographic analysis.

SDS-fibrin zymography in gradient polyacrylamide (SDSFZGP) SDS-fibrin gel was prepared as described by Kim and Choi (Kim et al., 1998; Choi and Kim, 1999; Kim and Choi, 1999). The composition of the linear gradient gel (5-20\%) is described in Table 1. One microgram of the supernatant from the culture broth that was diluted in a zymogram sample buffer (5 times) (consisting of $0.5 \mathrm{M}$ Tris, $\mathrm{pH} 6.8,20 \%$ SDS, 20\% glycerol, and $0.03 \%$ bromophenol blue) were loaded into a fibrin gel. After running the 
Table 1. Composition of linear gradient SDS-fibrin polyacrylamide gel

\begin{tabular}{lcc}
\hline Components/gel \% & $5 \%$ & $20 \%$ \\
\hline Solution A & $0.82 \mathrm{~mL}$ & $3.62 \mathrm{~mL}$ \\
Solution B & $1.00 \mathrm{~mL}$ & $1.00 \mathrm{~mL}$ \\
Bovine fibrinogen $^{\mathrm{A}}$ & $250 \mathrm{uL}$ & $250 \mathrm{uL}$ \\
Bovine thrombin $(1 \mathrm{U} / \mathrm{mL})$ & $50 \mathrm{uL}$ & $50 \mathrm{uL}$ \\
Distiled water & $2.78 \mathrm{~mL}$ & \\
Sucrose & & $0.75 \mathrm{~g}$ \\
SDS $(10 \%)$ & $50 \mathrm{uL}$ & $50 \mathrm{uL}$ \\
APS $(10 \%)$ & $50 \mathrm{uL}$ & $50 \mathrm{uL}$ \\
TEMED & $5 \mathrm{uL}$ & $5 \mathrm{uL}$ \\
\hline Total & $5 \mathrm{~mL}$ & $5 \mathrm{~mL}$ \\
\hline
\end{tabular}

Solution A: $30 \%$ acrylamide, $0.8 \%$ bis-acrylamide

Solution B: 1.5 M Tris-HCl (pH 8.8)

${ }^{A}$ Fibrinogen $(6 \mathrm{mg})$ was dissolved in solution $\mathrm{B}$ and then centrifuged to remove insoluble impurities

gel, it was soaked in a $2.5 \%$ Triton X-100 solution for $30 \mathrm{~min}$, then incubated in a reaction buffer $(30 \mathrm{mM}$ Tris, $\mathrm{pH} 7.4,200 \mathrm{mM} \mathrm{NaCl}$, and $0.02 \%$ Brij-35) at $37^{\circ} \mathrm{C}$ for $12 \mathrm{~h}$. The gel was stained with Coomassie blue for $1 \mathrm{~h}$, then destained. The digested bands were visualized as the non-stained regions of the fibrin gel.

Densitometric analysis of digested bands For quantification, the densities of the digested bands on the zymogram gel were analyzed by video densitometry using Bio 1D ver. 97.04 (Vilber Lourmat, France) (Kleiner and Stetler-Stevenson, 1994; Choi and Kim, 2001; Choi et al., 2001). The protein concentration was determined according to Bradford method (Bradford, 1976) using bovine serum albumin (BSA) as a standard.

\section{Results and Discussion}

Using a zymography analysis, it was found that Bacillus sp. DJ4 secretes seven extracellular fibrinolytic enzymes (EFEs; 68, $64,55,45,33,27$, and $13 \mathrm{kDa}$ ) in a culture broth. In gels with a high acrylamide concentration (15 and 12\%), seven EFEs were detected (Fig.1 B and C). As shown in Fig. 1 (B) and (C), low molecular protein bands (LMPBs; 45, 33, 27, and $13 \mathrm{kDa}$ ) showed good resolution; however, it was difficult to distinguish the high molecular protein bands (HMPBs; 68, 64, and $55 \mathrm{kDa}$ ) in high acrylamide concentration gels (15 and 12\%).

On the other hand, the gels with a relatively low acrylamide concentration (10 and $8 \%$ ) demonstrated good resolution of HMPBs, but LMPBs were not detected on the gel. As shown in Fig. 1 (D), the $13 \mathrm{kDa}$ band was found throughout the gel on the $10 \%$ acrylamide gel. Furthermore, in the $8 \%$ gel, two LMPBs (27 and $13 \mathrm{kDa}$ ) were not detected on the gel (Fig. 1, E).

In order to overcome this shortcoming, we applied a gradient gel system, which permits an excellent resolution of a broad range $(10-200 \mathrm{kDa})$ of proteins in a single gel

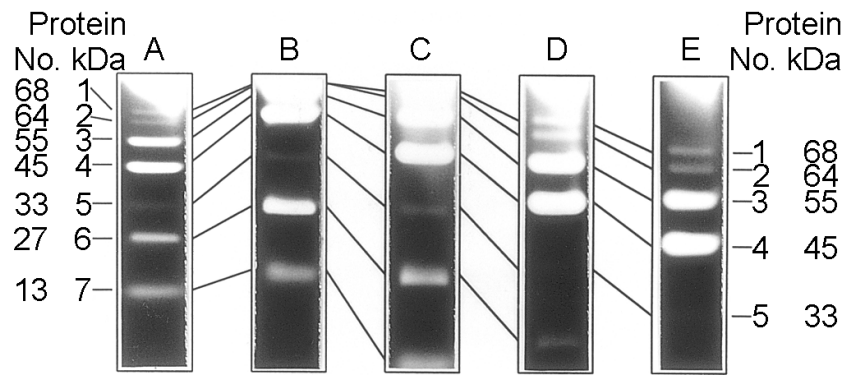

Fig. 1. Separation of the EFEs from the culture broth of Bacillus sp. DJ-4 on the five fibrin zymogram gel types. (A) 5-20\% linear gradient gel, (B) $15 \%$ gel, (C) $12 \%$ gel, (D) $10 \%$ gel, and (E) $8 \%$ gel.

(Matsudaira and Burgess, 1978) to the fibrin zymographic technique. In the SDS-FZGP (5-20\%) gel, as shown in Fig. 1 (A), up to $64 \mathrm{kDa}$ bands, including two bands smaller than 30 $\mathrm{kDa}$, were very well resolved in an improved gel system when compared to the corresponding polyacrylamide gels $(8,10$, 12 , and $15 \%$ ).

We also examined the relationship between an acrylamide concentration and the enzymatic activity of EFE from Bacillus sp. DJ-4 using densitometric analysis (Kleiner and StetlerStevenson, 1994; Choi and Kim, 2001; Choi et al., 2001). Table 2 describes the densities of all of the EFE that was detected in the various acrylamide concentration gels. The digested HMWBs in the low acrylamide concentration gels (8 and $10 \%$ ) showed higher enzymatic densities (high sensitivity in HMW area) than the other concentrations (15 and 12\%); however, LMWBs were not clear. This aspect limited the visualization and distinct separation of the LMWBs (Fig. 1, D and E).

On the other hand, the gel with a relatively high acrylamide concentration (12 and 15\%), as described in Table 2, revealed a low enzymatic density. But the LMWBs in these gels (12 and 15\%) showed clearer bands (good distinction in LMW area) than the low acrylamide concentration gels. These results demonstrate that the activities in the zymogram gels

Table 2. Densitometric analysis of separated EFEs on the five zymogram gels

\begin{tabular}{cccccc}
\hline $\mathrm{kDa} / \mathrm{gel}$ & $\begin{array}{c}\mathrm{Grad} \\
(5-20 \%)\end{array}$ & $15 \%$ & $12 \%$ & $10 \%$ & $8 \%$ \\
\hline 68 & $3.28^{\mathrm{a}}$ & $\mathrm{NS}$ & $\mathrm{NS}$ & 7.95 & 5.32 \\
64 & 3.12 & $\mathrm{NS}$ & $\mathrm{NS}$ & 8.07 & 5.45 \\
55 & 10.72 & 11.04 & 18.09 & 19.43 & 18.99 \\
45 & 13.42 & 17.25 & 19.43 & 22.11 & 20.01 \\
33 & 2.53 & 2.72 & 3.21 & 0.58 & 0.41 \\
27 & 6.32 & 14.49 & 10.32 & 0.36 & $\mathrm{ND}$ \\
13 & 7.58 & 8.32 & 8.57 & $\mathrm{ND}$ & $\mathrm{ND}$ \\
\hline
\end{tabular}

a: density $\left(\mathrm{cm}^{2}\right)$

NS: not separated band, ND: not detected band on the zymogram gel 
were relayed on the acrylamide concentration, which contributed to the diffusion of proteins through the gel matrices during the incubation period in an enzyme reaction buffer after the electrophoretic separation.

An SDS-FZGP (5-20\%) gel accepted these merits of high sensitivity (in the HMW area) and good distinction (in the LMW area), which were shown in the gels with low and high acrylamide concentrations, respectively (Fig. 1, A).

In this report, we applied SDS-fibrin zymography to the gradient gel for the analysis of EFE from Bacillus sp. DJ-4. We also described the effect of an acrylamide concentration on the enzymatic activities in zymogram gels. According to the enzymatic property, casein (for common protease), collagen (for collagenase or matrix metalloproteinase, MMP), gelatin (for gelatinase or MMP), cell wall (for cell wall hydrolase), and synthetic peptides could be used as protein substrates instead of fibrin. They could also be used in the proteomic approach.

\section{References}

Bradford, M. M. (1976) A rapid and sensitive method for the quantitation of microgram quantities of protein utilizing the principle of protein dye binding. Anal. Biochem. 72, 248-254.

Burg, B., Eijsink, V., Stulp, B. and Venema, G. (1990) Identification of autodigestion target sites in Bacillus subtilis neutral proteinase. Biochem. J. 272, 93-97.

Choi, N. S. and Kim, S. H. (1999) Application of fibrin zymography for determining the optimum culture time for protease activity. Biotechnol. Techniq. 13, 899-901.

Choi, N. S. and Kim, S. H. (2001) The effect of sodium chloride on the serine-type fibrinolytic enzymes and the thermostability of extracellular protease from Bacillus amyloliquefaciens DJ-4. J. Biochem. Mol. Biol. 34, 134-138.

Choi, N. S., Yoon, K. S., Lee, J. Y., Han, K. Y., and Kim, S. H. (2001) Comparison of three substrate (casein, fibrin, and gelatin) in zymographic gel. J. Biochem. Mol. Biol. 34, 531-
536.

Hames, B. D. (1981) A practical approach; in Gel Electrophoresis, Hames, B. D. and Rickwood, D. (eds.), pp. 71-77, IRL Press, Oxford and Washington D.C.

Heussen, C. and Dowdle, E. B. (1980) Electrophoretic analysis of plasminogen activators in polyacrylamide gels containing sodium dodecyl sulfate and co-polymerized substrates. Anal. Biochem. 102, 196-202.

Jeong, E. J. and Han, O. S. (2001) Purification and characterization of Bacillus subtilis protoporphyrinogen oxidase and pre-equilibrium behavior during oxidation of protoporphyrinogen 9. J. Biochem. Mol. Biol. 34, 39-42.

Kim, S. H. and Choi, N. S. (1999) Electrophoretic analysis of protease inhibitors in fibrin zymography. Anal. Biochem. 270, 179-181.

Kim, S. H. and Choi, N. S. (2000) Purification and characterization of subtilisin DJ-4 secreted by Bacillus sp. strain DJ-4 screened from Doen-Jang. Biosci. Biotechnol. Biochem. 64, 1722-1725.

Kim, S. H., Choi, N. S., and Lee, W. Y. (1998) Fibrin zymography: a direct analysis of fibrinolytic enzymes on gels. Anal. Biochem. 263, 115-116.

Kim, S. H., Choi, N. S., Lee, W. Y., Lee, J. W., and Kim, D. H. (1998) Isolation of Bacillus strains secreting fibrinolytic enzymes from Doen-Jang. Korean J. Microbiol. 34, 87-90.

Kleiner, D. E. and Stetler-Stevenson, W. G. (1994) Quantitative zymography: detection of picogram quantities of gelatinases. Anal. Biochem. 218, 325-329.

Kobayashi, T., Koike, K., Yoshimatsu, T., Higaki, N., Suzumatsu, A., Ozawa, T., Hatada, Y., and Ito, N. (1999) Purification and properties of a low-molecular weight, high-alkaline pectate lyase from an alkaliphilic strain of Bacillus. Biosci. Biotechnol. Biochem. 63, 65-72.

Matsudaira, P. T. and Burgess, G. R. (1978) SDS microslab linear gradient polyacrylamide gel electrophoresis. Anal. Biochem. 87, 386-396.

Walker, J. M. (1984) Method in Molecular Biology; in Proteins, Walker, J. M. (ed.) Vol. 1, pp. 57-62, Humana Press, Totowa, New Jersey. 